\title{
Negotiating the Digital Line: A Qualitative Inquiry into the Use of Communication Technologies in Professional Child and Youth Care Practice
}

Meghan Parry

Bachelor of Child and Youth Care, MacEwan University Alberta, Canada

bellefeuilleg@macewan.ca

Gerard Bellefeuille

Professor, Bachelor of Child and Youth Care, MacEwan University, Alberta, Canada

\section{Doi:10.5901/ajis.2015.v4n1s2p75}

\section{Abstract}

While social and communication technologies are changing the world at warp speed, little is known about how Child and Youth Care (CYC) practitioners are using these technologies in their work with children, youth, and families. This article reports findings from a qualitative study that explored potential boundary and ethical implications related to the integration of communication technologies by CYC practitioners in their professional relationships with children, youth, and families. The study also sought to examine what form of communication technologies is being used most commonly and the nature of agency policies, standards, and procedures that address the use of this technology by CYC practitioners with clients.

Keywords: boundaries, child and youth care, communication technology, ethics

\section{Introduction}

In this increasingly technology-driven world, the societal context in which Child and Youth Care (CYC) practitioners work is in a constant state of flux. As communication technologies are making the world an increasingly diverse and connected place, it is also changing fundamentally the way people communicate and relate to one another. Though social networking sites like Facebook and Twitter didn't even exist ten years ago, the social impact these technological innovations have had on the world has been extraordinary. Consider for example the use of social media in the 2011 Egyptian revolution, the Arab Spring, Iran's Green Movement, and its use as a vehicle for communication for those interested in social justice issues such as LGBT rights, anti-poverty movements, and democratic reform. On a practical level, communication technologies have also altered the way we interact professionally with children, youth, and families in our roles as CYC practitioners.

While there is no denying that we live in a new world, where social networking, cell phones, emails, texts, blogs, and Twitter, among other forms of technology, have become the dominant form of social communication, important ethical questions about the integration of these technologies into professional CYC practice have not been thoughtfully explored or discussed. The CYC practitioner-client relationship is supposed to be a therapeutic relationship based on trust, respect, and safety. To engage in "texting" or "friending" a client can certainly blur or even cross professional boundaries in ways that can lead to breaches in privacy, confidentiality, and to a host of other boundary violations.

The influence of technology over every aspect of our lives is, without question, an unstoppable force. However, the onus is on CYC practitioners to recognize the potential ethical issues related to the use of communication technologies with respect to maintaining appropriate professional boundaries and ethical practice (CYCAA, 2014). A CYC practitioner's relationship with their clients, albeit in a digital age, needs to be professional at all times. In acknowledging the potential risks inked to using communication technologies with clients, it is important to first define the concept of professional boundaries.

\subsection{Professional Boundaries Defined}

The term boundary denotes the concepts of limits, lines, or borders (Fewster, 2004). On a personal level, boundaries are guidelines, rules, or limits that we create to identify for ourselves what constitute reasonable, safe, and permissible ways 
to behave with others and how we will choose to react when someone steps outside those limits. Establishing clear boundaries is essential to maintaining a healthy, balanced lifestyle. Professional boundaries, in particular, differentiate what is therapeutic from what is not (Stuart, 2012). They form the foundation of trusting professional-client relationships. CYC practitioners, like other helping professionals, occupy a unique power relationship with their clients. This results from the CYC practitioner's position of authority and the access they have to the client's personal history, and the knowledge they have of the client's vulnerability and life circumstances. The power in the relationship also derives from the authority the CYC practitioner can exercise over the client with respect to benefits the client may or may not receive or the consequences that might be imposed on the individual.

In particular, CYC practitioners' use of a relational-centred approach to practice (Bellefeuille \& Jamieson, 2012) can present additional struggles for practitioners when it comes to defining appropriate professional boundaries. Because a relational-centred approach requires "being-with" and "being in the moment" with others, this approach demands a high degree of ingenuity, creativity, and openness on the part of the CYC worker. Child and Youth Care is different from other helping professions in that it focuses primary on life-space work - that is, the spaces in which the lives of children, youth, families, and communities unfold. Life-space intervention allows for greater freedom in bringing one's authentic self to the professional-client relationship. As Garfat and Fulcher (2011) explain, "there is no other form of intervention which is so immediate, so grounded in the present experiencing or, one might say, so everyday" (p. 8).

This challenge to define professional boundaries is further complicated by the introduction of communication technologies into the mix. Practicing from a life-space perspective in this age of technology can lead to some significant ethical challenges. Social media, cell phones, and other forms of technology represent much more than tools for communication. They change how people relate and interact, how relationships are formed, and how people complain, celebrate, discover, and create. As a result, CYC practitioners must be cognizant of the potential ethical and boundary issues associated with the use of these technologies in their work with children, youth, and families. For example, where should a CYC practitioner draw the line when it comes to communication technologies? Is it ever okay to accept a client's friending request? Is looking at a client's profile or blog an invasion of privacy? Can posting on social media sites make the CYC worker vulnerable to the unintended use of their own private information?

\subsection{CYC Code of Ethics}

A professional code of ethics sets out a collection of standards of behaviours that professionals are expected to uphold in their professional practice. The Alberta CYC code of ethics (CYCAA, 2014), for example, requires that CYC practitioners "take responsibility for ensuring that their relationships with their clients are therapeutic." Yet, despite our growing understanding that the use of the Internet, social media, and other forms of communication technologies blurs the line between what we think of as private and public, the potential ethical implications of the use of these technologies for professional CYC practice have not been thoroughly investigated. Hence, the aim of this exploratory study was to examine the use of social media and communication technologies by CYC practitioners and to invite a timely conversation about ethical challenges and opportunities that arise in various practice settings when CYC practitioners use social media, both as individuals and as a collective.

\section{Research Design}

The study was grounded in an interpretive world view and social construction paradigm that looks for "culturally derived and historically situated interpretations of the social life-world" (Crotty, 2003, p. 67). Given the interpretive nature of this study, a qualitative, exploratory research design was used as the method of inquiry. The specific questions included the following:

1. How do CYC practitioners use social media, cell phone texting, and other forms of communication technologies with their clients and colleagues?

2. What are the perceived and observed potential or actual ethical issues associated with use of social media, cell phone texting, and other forms of communication technologies by CYC practitioners with their clients and colleagues?

3. Are there policies and procedures put in place by agencies in order to help guide ethical practice and inform practitioners of appropriate boundaries in regards to the use of communication technologies with colleagues and clients? 


\subsection{Research Participants}

A non-probability, purposive sampling strategy was used to recruit 30 participants for the study. Participants who met the following characteristics were recruited: Individual had to be at least 18 years of age and work in the CYC field as a practitioner.

\subsection{Data Collection and Analysis}

Data collection strategies included open-ended and close-ended questions administered by questionnaires, face-to-face interviews, and various communication technologies including email, online chats, and social media. Data analysis, which was conducted during and after data collection, involved the identification of dominant themes and the clustering of themes into categories (Merriam, 1988). Closed-ended data was analyzed using descriptive statistics and depicted in frequency distribution tables.

\section{Findings}

RQ 1. How do CYC practitioners use social media, text messaging, and other forms of communication technology with their clients and colleagues and what are they using?

CYC practitioners on a daily basis to communicate with both clients and co-workers are using communication technology. The most popular forms of online communication were emails, text messaging, and Facebook (see Table 1 below). Of the 30 participants, 26 (86\%) reported actively using text messaging, 21 (70\%) used emails, and 15 (50\%) participants reported using Facebook to communicate with their clients. To communicate with co-workers, 28 (93\%) participants used text messaging, 22 (73\%) used email, and 7 (23\%) used Facebook.

Table 1. Types of Communication Technology used by CYC Practitioners ( $\mathrm{N}=30)$ with Clients and co-workers

\begin{tabular}{ccc}
\hline Text Messaging & Emails & Facebook \\
\hline Clients $(n=26)$ & Clients $(n=21)$ & Clients $(n=15)$ \\
Co-workers $(n=28)$ & Co-workers $(n=22)$ & Co-workers $(n=7)$ \\
\hline
\end{tabular}

The majority of the participants reported using text messaging and email to keep in touch with their clients, send out reminders for appointments and upcoming meetings, and for the simplicity and ease in reaching clients.

"I use text messages with clients to communicate about issues as well as appointments." (Participant A)

"We use text messaging to quickly communicate amongst each other. Text messaging allows us to easily update co workers in the moment if a situation arises with a particular client." (Participant E)

It was also general practice to use text messaging, email, and Facebook as the primary means of communication, without having to meet in person. The general rationale expressed by participants for using electronic forms of communication with clients is that they have become acceptable to and expected by their clients.

"To maintain easy contact with clients." (Participant F)

"I have on occasion placed private messages to family and youth on their Facebook accounts." (Participant B)

"I have used Facebook during investigations to find family, find information out about [a] current situation and to locate teens." (Participant D)

RQ 2. What are the perceived and observed potential or actual ethical issues associated with use of social media, cell phone texting, and other forms of communication technology with clients and colleagues.

The dominant theme among participants was that while they recognized the potential risk issues associated with confidentiality, they did not express any ethical concern over the manner in which they used electronic forms of communication.

"I have not encountered any ethical dilemmas, it is not mandatory that any staff give their cell phone number to any of the kids, it is by their own choice." (Participant G) 
"There aren't any ethical dilemmas, other than keeping contact information confidential." (Participant I)

"Sometimes clients text me after hours. I set out very clear boundaries about when I will respond to texts, but sometimes it is difficult to ignore." (Participant $M$ )

"To be honest, I do not think that my agency has guidelines to deal with negative repercussions of technology use." (Participant P)

A few of the participants also expressed that they felt comfortable using text messaging and Facebook when discussing sensitive issues such as (a) clients who are experiencing thoughts of suicide and self-harm, (b) clients experiencing difficult times (e.g., on a home visit), (c) updating staff about current situations in which youth are involved, (d) creating and following up with youth about safety plans, (e) contacting colleagues and other professionals regarding support and advice, or other work related matters, and (f) ensuring treatment plans are being implemented and followed by staff.

RQ 3. Are there policies and procedures put in place by agencies in order to help guide ethical practice and inform practitioners of appropriate boundaries in regards to the use of communication technology with individuals.

For the majority of the research participants, social networking policies were non-existent in their place of employment. Nineteen (63\%) of the participants indicated that they did not know of any policies and procedures or they said that their place of employment had no formal policies or procedures in place about how to work with communication technology. A number of participants stated that the only documented agency policy was that they exercise their own judgement when using communication technology with clients. A small number of participants $(n=6)$ indicated that they were required to secure a copy of all communications with their clients but this policy was not in written form.

\section{Discussion}

As communication technology becomes a more regular means of connecting between CYC practitioners and clients, it is time to step back and examine-from an ethical point of view-the underlying purposes for and potential implications of the use of electronic communication. Clearly communication technologies are not going away but, by the same token, standards of professional practice are not about to change. CYC practitioners are professionals and, as such, are expected to model a high standard of ethical behaviour. CYC practitioners also occupy a position of trust with clients and must be held accountable for their "cyberconduct." In light of the fact that nothing is truly private when you communicate online and that nothing is ever fully erased, there is a very real potential that unintended consequences may surface in the future. The results of this study are interesting. Interacting with clients on social networking sites and online has become "normal" practice. Yet, none of the 30 study participants felt there was any risk associated with the manner in which they used communication technology with clients and co-workers. This finding raises two very important and timely questions for the profession of CYC.

The first question arises from the demonstrated lack of awareness or concern over the potentially public nature of communication technologies by CYC practitioners in relation to their use with co-workers and clients. Although communication technologies provide new ways to interact and communicate, what are the ethical impacts of these technologies on client privacy, confidentiality, professional boundaries, and the reputation of CYC practitioners and the organizations that they work for? The use of communication technologies in CYC practice has received very little attention in professional CYC literature and has yet to be fully understood and thoroughly studied. It is reasonable to assume that the ongoing emergence of communication technologies will continue to influence the way CYC is practiced. Therefore, the need to develop professional communication technologies guidelines and policies to ensure that CYC practitioners are not only aware but also understand the ethical implications inherent to their use is essential.

Second, although this preliminary study only involved 30 participants, the results as they relate to the philosophical core of relational-centred practice are worrisome. Relational-centred practice is founded on the core assumption that "the self is formed and lived out in relationship" (Bellefeuille, Hedlin, McGrath, 2012, p. 133). From this stance, emotional wellbeing is predicated on having satisfying personal relationships with others. From this perspective, relational-centred practice proposes that a central human necessity is the establishment of authentic and mutual connection in the professional-client relationship. What is worrisome is the extent to which CYC practitioners are connecting with clients online rather than in face-to-face interaction. What are the implications of an increasing reliance on communication technologies as a way to interact with clients and co-workers on our ability to practice from an interpersonal relationalcentred perspective? Further research is clearly needed to gain greater insight into the impact that communication technologies are having on the quality of the therapeutic relationships between CYC practitioners and their clients.

In conclusion, striking a healthy balance between communicating professionally with clients through the use of 
communication technologies and maintaining professional ethical standards is challenging and will require further study.

\section{Acknowledgments}

We wish to thank fourth-year CYC student Amelia Gregresh for her assistance in the design and implementation of the research and with the editing of this article.

\section{References}

Bellefeuille, G., Hedlin, C., \& McGrath, J. (2012). Evidence-based practice informed by relational-centred inquiry. The International Journal of Interdisciplinary Social Sciences, 6(4), 131-142.

Crotty, M. (2003). The foundation of social research: Meaning and perspective in the research process. Thousand Oaks, CA: Sage Publications.

CYCAA (2014). Code of ethics. Retrieved November 2014, from http://www.cycaa.com/about-us/code-of-ethics

Fewster, G. (2004). Just between you and me: Personal boundaries in professional relationships. RCYCP, 17(4), 8.

Garfat, T., \& Fulcher, L. (2011). Characteristics of a relational child and youth care approach. Relational Child and Youth Care, 14(1/2), 7-9.

Merriam, S.B. (1988). Case study research in education: A Qualitative Approach. San Francisco, CA: Jossey-Bass.

Stuart, C. (2012). Shaping the rules: Child and youth care boundaries in the context of relationship. Bonsail. In G. Bellefeiule \& F. Ricks (Eds.), Standing on the precipice: Inquiry into child and youth care practice (pp. 135-169). Edmonton, AB: MacEwan Press. 
